\title{
ESPORTE E IDEOLOGIA NO PERIÓDICO ON-LINE EL PAÍS BRASIL
}

Cristiano Mezzaroba ${ }^{1}$

Fernando Gonçalves Bitencourt²

\begin{abstract}
Resumo: Neste estudo documental, de abordagem qualitativa e exploratória, identificamos e analisamos 103 reportagens no periódico online El País Brasil, produzidas e veiculadas entre janeiro/2019 e fevereiro/2020. A escolha pelo referido jornal ocorreu pela percepção costumeira em relação ao seu posicionamento progressista quando comparado à maioria dos grandes jornais brasileiros. Utilizando-se da análise crítica da ideologia de Thompson (2011), observamos que no conjunto das reportagens coletadas puderam ser elaborados 5 agrupamentos temáticos, os quais foram analisados separadamente, embora consideramos um grau de interdependência entre todos eles: (1) machismo - 39 reportagens; (2) política e fascismo - 20 reportagens; (3) racismo - 16 matérias; (4) mercadorização e tecnologias - 16 reportagens; e, (5) homofobia e preconceitos/assédio sexual - 12 reportagens. Concluímos que o esforço do periódico em pautar temas importantes da política contemporânea é limitado pela sua estrutura conservadora, tanto na ordem do discurso quanto no dos interesses econômicos, e propriamente ideológico, pois que sob a aparência progressista junta-se aos esforços de manutenção da ordem do poder.
\end{abstract}

Palavras-chave: esporte, ideologia, El País Brasil.

\section{Sport and ideology in the online newspaper El País Brasil}

Abstract: In this documentary study, with a qualitative and exploratory approach, we identified and analyzed 103 reports in the online newspaper El País Brasil, produced and published between January, 2019 and February, 2020. The choice for the referred newspaper occurred due to the usual perception in relation to its progressive positioning when compared to the majority of the great Brazilian newspapers. Using the critical analysis of the ideology of Thompson (2011), we observed that in the set of reports collected, 5 thematic groups could be elaborated, which were analyzed separately, although we consider a degree of interdependence between them all: (1) machismo/male chauvinism - 39 reports; (2) politics and fascism - 20 reports; (3) racism - 16 articles; (4) commodification and technologies - 16 reports; and, (5) homophobia and prejudices/sexual harasment - 12 reports. We conclude that the journal's effort to focus on important themes of contemporary politics is limited by its conservative structure, both in the order of discourse and economic interests, therefore properly ideological, since under the progressive appearance it joins efforts to maintain the order of power.

Keywords: sport, ideology, El País Brasil.

1 Professor adjunto no Departamento de Educação Física da Universidade Federal de Sergipe (UFS),cristiano_mezzaroba@yahoo.com.br

2 Professor Titular do Instituto Federal de Santa Catarina/Campus São José, ferbit@ifsc.edu.br 


\section{Introdução}

A ascensão da extrema direita no Brasil fez reaparecer, no discurso cotidiano, o problema da ideologia. Termo com histórico ligado às concepções de esquerda e produto do trabalho de intelectuais, notadamente desde que Marx formulou sua teoria da falsa consciência, o termo sofreu mais uma importante torção ao transformar-se em categoria acusatória contra a mesma esquerda que o forjou. Como reflexo tardio e deformado do espelho da história, vemos Napoleão acusar Destutt de Tracy de ideólogo cotidianamente, numa espécie de caleidoscópio em que gênero, comunismo e Paulo Freire se confundem na visão monocular, espelhada e estreita em que nos metemos nos últimos anos.

Como conceito operativo das Ciências Humanas e da Filosofia, "Ideologia" parece ter perdido o fôlego mais ou menos ao final dos anos setenta do século passado, quando se anunciava o fim das meta narrativas, o fim da história, a vitória do capitalismo tardio em sua versão neoliberal financeirizada e a decadência do comunismo real. Mas é justamente cinquenta anos depois, quando o simbólico se afirma como uma arquitetura da experiência humana e a cultura é nossa casa, que o termo ganha força discursiva em nossa vida ordinária e nos surpreende como se nos deparássemos com um velho fantasma.

Esporte e ideologia atravessaram o século vinte de mãos dadas. Mais velha, a ideologia conduzia o esporte em sua passagem. As práticas de lazer aristocráticas e burguesas, do tempo em que o ócio era preenchido pelo sport, prática livre e desinteressada, ganharam dimensão global e o uso dos corpos como discurso político chegou aos governos nacionais, o que o NacionalSocialismo na Alemanha e a Guerra Fria demonstram muito bem ao se considerar os esforços de vitória nos Jogos Olímpicos, por exemplo, que as diferentes nações se impuseram.

As disputas do Século XX estão adormecidas. O capital é a força motriz da sociedade global e o esporte é uma expressão práticosimbólica da sociedade do espetáculo e do consumo. Entretanto, ainda que as utopias que prevaleceram nos últimos dois séculos o fim do capital e a igualdade entre os homens ${ }^{3}$ parecem também adormecidas, ao menos na esfera macropolítica -

3 Utilizamos a expressão "homem", com o sentido de humanidade, para expressar o espírito da modernidade nos séculos XIX e XX. Por certo, a humanidade não é feita apenas de "homens", exceto no discurso machista que ainda resiste. 
identificamos na luta pelos direitos civis o surgimento de novas demandas ao cenário político, as quais chegam no momento atual como potência de luta para o que se convencionou chamar de "minorias". À identidade geopolítica e econômica, somaram-se novos sujeitos políticos a reivindicar direitos das mais variadas ordens.

É nesse espaço-tempo que o esporte se configura, por um lado, como ideólogo da velha fórmula da "igualdade de chances" e do "que vença o melhor!", sustentáculo do discurso liberal capitalista, espécie de darwinismo social e, em contrapartida, a despeito de sua estrutura conservadora, põe em discussão os problemas políticos que identidade/alteridade e, por certo, da diversidade sugerem.

Mas o esporte, enraizado que é na cultura contemporânea, talvez não passasse de uma pálida presença não fosse sua associação aos meios de comunicação. A intensa apresentação, os discursos recorrentes sobre seus valores e virtudes, o caráter espetacular dos feitos atléticos, a interminável "falação esportiva" (ECO, 1984; BETTI, 1998) produziram um evento de alcance massivo, cujo valor econômico é incomensurável. Ideologia e esporte são, no século $\mathrm{XX}$, estruturados pelo discurso midiático, ele mesmo ideológico em sua organização e funções sociais.

É nesse sentido que desenvolvemos este estudo, de cunho exploratório (TRIVIÑOS, 1995) e caracterizado como uma pesquisa documental (GIL, 19965), com o objetivo de refletir sobre o discurso midiático em torno do esporte. Especificamente, analisa reportagens esportivas produzidas e veiculadas no periódico online El País Brasil, no período de janeiro/2019 a fevereiro/2020.

A escolha pelo referido jornal ocorreu pelo seu posicionamento progressista ${ }^{6}$ em relação à maioria dos demais portais midiáticos

4 Segundo TRIVIÑOS (1995, p. 109), a pesquisa do tipo exploratória permite ao investigador "aumentar sua experiência em torno de determinado problema." Desta maneira, "o pesquisador parte de uma hipótese e aprofunda seu estudo nos limites de uma realidade específica, buscando antecedentes, maior conhecimento" (Idem, idem).

5 Para Gil (1996, p. 51), a pesquisa documental "[...] vale-se de materiais que não receberam ainda um tratamento analítico, ou que ainda podem ser reelaborados de acordo com os objetos da pesquisa."

6 Conforme relembra Gheno (2017), p. 30), "El País nasceu afirmando-se como um jornal liberal, propulsor das democracias e com vocação global.", e ainda, segundo o mesmo autor, "[...] Consolida-se, assim, como um importante portal de informações com vocação internacional e alternativo à imprensa nacional estabelecida." (GHENO, 2017, p. 9). Ocorre que no desenvolver dos anos, conforme Molina (2008) citado por Gheno (2017, p. 31), o diário espanhol, é possível visualizar "[...] uma tendência política de centro-esquerda, apesar de publicar diversas opiniões de seus 
brasileiros, em que foi possível visualizarmos transformações discursivas em relação ao contexto esportivo e questões ideológicas contemporâneas no Brasil e no mundo. Leal e Johnson (2019, p. 25) afirmam que "[...] o El País Brasil defende as minorias e a diversidade.", oportunizando debates e análises em relação às fake news, transgêneros, corrupção, educação, meio ambiente (questão amazônica, por exemplo), economia, empoderamento feminino, violência contra a mulher, direitos LGBTQ+ etc., em que é possível se observar "[...] jornalistas com relativa independência, defesa de valores democráticos, apreço por oferta de contraditório e de abordagens alternativas e com diversidade de pontos de vista" (LEAL \& JOHNSON, 2019, p. 26).

Entrevistando profissionais do referido veículo tanto na Espanha como no Brasil e também por meio de indicadores de acesso digital quanto à edição brasileira, os autores consideram que $\circ \mathrm{El}$ País Brasil é percebido à esquerda da sua real posição, ou seja, quando este é contrastado com os grandes jornais brasileiros (Folha de São Paulo, O Globo, O Estado de São Paulo - os quais funcionam como mecanismos da indústria cultural, com posições políticas e econômicas no espectro da direita), conjunto "marcado pela alta concentração empresarial, pela similitude de posições ideológicas e pela baixa capacidade de vocalização do contraditório" (LEAL \& JOHNSON, 2019, p. 15), o El País Brasil passa a ser considerado como progressista, embora seus produtores e jornalistas definam seu posicionamento político como de centro?.

Para a operacionalização deste estudo, foram identificadas 103 (cento e três) reportagens que geraram os seguinte eixos de análise: (1) machismo; (2) política e fascismo; (3) racismo; (4) mercadorização e tecnologias; e (5) homofobia e preconceitos/assédio sexual. O texto está dividido em três partes

\footnotetext{
colaboradores. Na cobertura econômica, é considerado um jornal conservador, porém é radicalmente pautado por questões sociais."

7 "Na Espanha e no Brasil, o jornal afirma que seu posicionamento político não é de esquerda e nem de direita, mas de centro [...]. Ortellado e Moretto (2017; 2016) afirmam, em estudos sobre a polaridade ideológica de veículos de comunicação jornalísticos no Brasil, que o El País é o mais próximo ao posicionamento neutro dentre os 82 pesquisados, mas com leve inclinação à direita." (LEAL \& JOHNSON, 2019, p. 20). Ampliando a discussão, esses mesmos autores escrevem que: "Embora o El País enuncie um posicionamento editorial liberal de centro, o Reuters Institute Digital News Report 2017 não apenas identifica o jornal no topo do mapa de audiências de notícias online no jornalismo digital na Espanha, mas, também, posicionado à esquerda do espectro ideológico, deixando o seu principal concorrente impresso e digital El Mundo consideravelmente distante no quadrante à direita do centro. O diferencial do El País para os usuários digitais, conforme o relatório do Reuters Institute (NEWMAN et al., 2017, p. 93), está na 'compreensão de questões complexas', 'pontos de vista fortes' e 'notícias confiáveis'. (LEAL \& JOHNSON, 2019, p. 22)
} 
além desta introdução e as devidas considerações finais. Primeiro, discutimos o que tomamos por "ideologia" nos termos deste trabalho, seguindo as contribuições de Zizek (1996) e Thompson (2011). Em seguida, contextualizamos quanto ao periódico El País Brasil para, por fim, analisar as mencionadas reportagens sob a concepção crítica de análise da ideologia, conforme Thompson (2011).

\section{Sobre o conceito de Ideologia}

Todo conceito utilizado em um trabalho de reflexão merece argumentos que o justifique. Entretanto, quando se trata de Ideologia a exigência surge como se fosse um imperativo. Primeiro, porque o termo ganhou importância no discurso político atual, principalmente no Brasil. Segundo, porque compreendemos que ainda há força teórica no conceito de Ideologia.

Sobre o primeiro aspecto, um parágrafo. O termo Ideologia voltou a fazer parte do discurso político nacional. 'Ala ideológica do governo', 'ideologia de gênero', 'ideologia comunista', entre outras expressões, pululam nos meios de comunicação, nos discursos políticos e no imaginário social do Brasil contemporâneo, das classes baixas às classes mais altas, de norte a sul do país. $O$ termo vem, de modo geral, carregado de uma carga acusatória, que resulta violenta e excludente, a um outro que faz parte de, ou apologia $a$, alguma ideia nefasta e perigosa ao bem comum. $O$ que surpreende, mas talvez não o devesse, é que o termo acaba sendo incorporado pelo discurso conservador complexo e difuso, distorcendo, deste modo, a tradição crítica do conceito e se apropriando do esforço de neutralização que o mesmo sofreu em sua história. É em virtude do retorno do termo como uma espécie de discurso nativo que optamos por utilizá-lo.

O segundo aspecto, que merecerá um pouco mais de atenção, está no caráter propriamente crítico que reconhecemos no termo ideologia e seu papel na manutenção da ordem social, do status quo, em suma, do poder. Para poder operá-lo, faremos uma breve explanação de nosso suporte teórico e do modo como o utilizamos para as interpretações que aqui realizamos. Seguiremos inicialmente Zizek (1996). Ao formular a reconstrução do conceito, o autor apresenta suas reflexões acerca da ideologia no que poderíamos chamar de seu três modos de aparição: "em si"; "para si" e "refletida em si mesmo". Essa tríade hegeliana, como 
diz o autor, é acompanhada do paradoxo inerente à própria ideologia, qual seja, que a tentativa de fuga da ideologia nos puxaria de volta a ela.

A Ideologia "em si" estaria fundada na tradição lluminista e é marcada pelas falsas ideias, ou ideias distorcidas, que se dariam em virtude de interesses que o autor chama de "patológicos" (medo, poder, forças da natureza). Em sentido estrito, ideologia seria a "legitimação racional da ordem existente" (ZIZEK, 1996, p. 19) levados a efeito através de falsas premissas. Como no nível discursivo não há realidade objetiva, pura, que possa ser alcançada sem o filtro da linguagem, o lugar de análise da ideologia é, já, também ideológica. O paradoxo da ideologia, ou sua ambiguidade, reside, nesta construção, na impossibilidade de se produzir discursos e sentidos que acessem a realidade diretamente e, portanto, não há lugar fora da ideologia.

A ideologia existe como uma "matriz geradora que regula a relação entre o visível e o invisível, o imaginável e o inimaginável, bem como mudanças nessa relação" (ZIZEK, 1996, p. 7). Mas isso não implica que tais relações tenham a ver com ilusão, com imagem ou ideia equivocada e distorcida da realidade social. Isso nos afasta, por princípio, da análise da ideologia como "falsa consciência". Essa primeira premissa é necessária pois que é justamente esse um dos pontos mais controversos da análise da ideologia, qual seja, a de que seria possível ocupar um lugar neutro, não-ideológico, ou ainda, supra-ideológico que nos fizesse capaz de dizer o que é a realidade e o que é e quem possui a verdadeira consciência. A despeito disso, não se trata de abandonar o caráter crítico do termo, mas de procurar embasálo em sua condição de possibilidade analítica, ou melhor, interpretativa da experiência social.

A segunda perspectiva, da ideologia "para si", está baseada nas premissas bastante conhecidas de Lovis Althusser sobre os Aparelhos Ideológicos do Estado (AIE) e a materialização da ideologia nas instituições, objetos, rituais etc. Isso implica em encontrar na produção material do sentido uma ordem racional da ideologia. Isto é, na medida em que o poder cria ou se apropria do mundo material, acaba por the impor um conjunto de sentidos cuja direção é a manutenção da ordem do poder. Exemplifica Zizek (1996, p. 19): 
A denúncia direta da noção fascista de Volksgemeinschaft [comunidade popular], como um chamariz enganador que oculta a realidade da dominação e da exploração, não leva em conta o dado crucial de que essa Volksgemeinschaft materializou-se numa série de rituais e práticas (não apenas comícios de multidões e desfiles, mas também campanhas em larga escala para ajudar os famintos, atividades esportivas e culturais organizadas para os trabalhadores etc), que produziram, ao serem executadas, o efeito da Volksgemeinschaft.

Os AlEs foram bastante discutidos no Brasil dos anos 70 e 80 do século passado, inclusive na discussão do papel do esporte na afirmação da ideologia dominante. O ufanismo futebolístico, o programa "Esporte Para Todos" e a disseminação de campos, ginásio, pistas e aparelhos para a prática esportiva, por exemplo, faziam (fizeram) parte dos esforços do regime ditatorial cívico/militar de disseminação de valores cívicos, patrióticos de refundação da nação.

No último elemento da reconstrução do termo, "ideologia refletida para si mesma", em que "em si" e "para si" se encontram, ocorre, para Zizek (1996, p. 19) a "desintegração, autolimitação e autodispersão da noção de ideologia". As críticas à Tese da Ideologia Dominante, tese que atravessou os séculos XIX e XX desde Marx, afirmam que ela deixa de ser o amálgama da vida social e passa exercer seu papel de modo fragmentado, agindo em campos dispersos, heterogêneos e microscópicos, tornando marginal seu papel na reprodução da ordem social.

As teses do capitalismo tardio, do fim da história ou o fim da era das ideologias afirmam que não é mais a ideologia, mas sim forças extra ideológicas que penetram no corpo social. A associação dos meios de comunicação com o mercado faria com que os indivíduos agissem não mais baseados em crenças ou ideologias, mas, contornando a ideologia, a reprodução do sistema se daria diretamente pela coerção, pelas leis, pelo Estado etc. Mas é justamente nesse momento, em que se sugere a fragmentação, dispersão e/ou contorno da ideologia que a ideologia se confirma em sua força de manutenção da ordem e do poder.

Neste jogo especular em que o "em si" e o "para si" se encontram, que a ideologia se apresenta no centro do que se apresentou como "extra ideológico", que a força da ideologia renasce. Primeiro, porque a coerção econômica e as leis materializam-se em práticas e crenças; segundo, porque a 
consciência que se adapta ao capitalismo tardio, ou era pósideológica, é ela mesma ideológica, na medida que, em seu cinismo, funciona como mecanismo de reprodução social. Em nome da moral, da tradição e das normas, das noções de liberdade individual, bem como na ação do mercado ou nos discursos midiáticos, um conjunto de forças é agenciado para legitimação e manutenção do status quo.

O que se configura nesta breve reconstrução do conceito de Ideologia provoca ao menos duas perguntas: Existe um lugar fora da ideologia? Se sim, ou não, quais implicações para a análise social a partir do termo?

A resposta lacaniana de Zizek (1996) à primeira questão é interessante. Para haver esse lugar, ele só pode ser um espaço que jamais pode ser ocupado: é a casa vazia estruturalista, o significante zero. Uma vez que o "real" não pode ser acessado em seu todo, pois que atravessado pelo simbólico, e que também o simbólico não pode alcançar o todo, pois que sempre há uma sobra de significante, seria nesse hiato, nessa espécie de aquém, e que o autor vai chamar de "espectro", que o pré-ideológico seria possível. Nas palavras do autor:

Portanto, o "cerne" pré-ideológico da ideologia consiste na aparição espectral que preenche o buraco do real. É isso que todas as tentativas de traçar uma clara linha separatória entre a "verdadeira" realidade e a ilusão (ou de fundamentar a ilusão na realidade) deixam de levar em conta: para que emerja (o que vivenciamos como) a "realidade", algo tem que ser foracluído ${ }^{8}$ dela - em outras palavras, a "realidade", tal como a verdade, nunca é, por definição, "toda". O que o espectro oculta não é a realidade, mas seu "recalcamento primário", $\mathrm{X}$ X irrepresentável em cujo "recalcamento" fundamenta-se a própria realidade. (ZIZEK, 1996, p.

27)

Não podemos, portanto, estar no lugar externo à ideologia, uma vez que ao preenchermos a casa vazia e ocuparmos um lugar no campo do simbólico, passamos a significar, de modo que quando nos posicionamos acerca de um evento da vida social já ocupamos um lugar no discurso ideológico. Aliás, o autor

8 "A foraclusão é o mecanismo através do qual se produz a rejeição de um significante fundamental para fora do universo simbólico do sujeito". (ROUDINESCO \& PLON, 1998, p. 245). Este significante foracluído, ou rejeitado, "[...] não é integrado no inconsciente e retorna sob forma alucinatória no real do sujeito". (Idem, idem). 
supracitado aponta para o fato que nós mesmos não podemos dizer que estamos ou não na ideologia, uma vez que apenas o Outro pode nos colocar nesse lugar. Ser ideológico é sempre uma relação e depende, portanto, do Outro. Como proceder, então, para não cairmos na armadilha da ideologia? Daqui seguiremos com Thompson (2011).

Para esse autor, a análise da ideologia é uma atividade crítica, que não pode ser separada da reflexão sobre as relações de dominação. Os fenômenos ideológicos são formas simbólicas, portanto carregados de significado, que estruturam relações de poder. Considerados em seus contextos sociais e históricos, portanto econômicos e políticos, um conjunto de símbolos funciona como suporte do poder para estabelecer estruturas de dominação, legitimando, sem a necessidade do uso da coerção física, o próprio poder do qual emana.

Assim como aponta Zizek (1996), também Thompson (2011) considera que as formas simbólicas não precisam ser necessariamente ilusórias ou errôneas, basta a elas que, como mencionado, funcionem para estabelecer relações de poder $e$ dominação. As formas simbólicas são, em geral, tudo que sirva de suporte a um significado. Como o trabalho do autor está ligado ao estudo dos meios de comunicação de massa - e aqui está a justificativa para sua escolha - as formas simbólicas que aqui importam são as falas, imagens e textos, produzidos, em nosso caso específico, pelo periódico El País Brasil em seu trabalho diário de informar e formar opinião.

A "concepção crítica" de análise da ideologia proposta por Thompson (2011, p. 73) está, assim, fundamentada na interpretação das formas simbólicas ao considerar o fato de que a ideologia opera por meio de alguns dos seguintes modos, quais sejam, por: legitimação, dissimulação, unificação, fragmentação e reificação; cada uma delas com suas estratégias típicas.

A primeira estratégia, a de legitimação, se dá por meio de discursos lógicos e encadeados, cuja racionalidade procura justificar ideias e posições e convencer os interlocutores. Se dá também como esforço universalizante, ao sugerir que interesses particulares, privados ou de pequenos grupos sejam corroborados ao produzirem o sentimento de que são os interesses comuns a todos. Por fim, narrativas que encadeiem o passado ao presente, postulando tradições eternas e imutáveis, completam o quadro no qual um esforço de legitimação pode ser investigado. 
A segunda estratégia, a dissimulação, na qual a dominação é obscurecida, negada ou ocultada, apoia-se em figuras de linguagem que provocam deslocamentos, associações, ilações contingentes, superficiais ou ilusórias no discurso. $O$ uso de eufemismos, metáforas, metonímias e sinédoques provoca deslocamentos na relação símbolo significado, numa espécie de jogo com a realidade que pode obnubilar o entendimento e produzir inferências, e, desse modo, dissimular as relações de poder.

Os terceiro e quarto modos de pôr em funcionamento o discurso ideológico são, segundo Thompson (2011), unificação e fragmentação, respectivamente, que, em síntese são constructos simbólicos que, ou reforçam padrões e reforçam unidades, ou, ao contrário, destacam as diferenças implantando desigualdades, discriminação e expurgo do outro. Em ambos os casos, seja pela unidade, seja pela diferença, um sistema de identidade e alteridade, "nós" e "outros" ajudam a produzir discursos de ordem, pertencimento e poder.

Por fim, o último dos modos de operação tem uma longa história na filosofia e nas ciências humanas. Para o autor, a reificação consiste em naturalizar, petrificar, congelar processos históricos e culturais, retirando seu caráter de construção social, resultante da agência humana, transformando a realidade em algo, portanto, imutável, atemporal, a-histórica. Do mesmo modo, usando verbos na passiva, mascara a presença dos agentes sociais responsáveis pelo desenvolvimento das ações, impedindo que se perceba 0 papel da sociedade e dos grupos de interesse na produção da própria dominação.

Essas modalidades de produção simbólica, finalizando, são fundamentos da análise crítica da ideologia proposta pelo autor, e estão na base das interpretações que aqui realizamos. A reconstituição do conceito de ideologia que realizamos nos ajuda a compreender o papel e os riscos da análise da ideologia. Temos clareza que ocupamos um lugar no espaço social e é desde este locus que formulamos nossos entendimentos. A crítica da ideologia é, em síntese, uma possibilidade de crítica dos sistemas simbólicos e seus significados, em especial do discurso midiático, em seu papel de informar e formar a sociedade (com seus consensos e dissensos). 


\title{
Contextualizando o periódico online "El País Brasil"
}

Para melhor compreensão do jornal digital El País Brasil, cabe uma breve contextualização em relação ao jornal espanhol El País, por este ser matriz daquele periódico. Trata-se de um veículo de propriedade do Grupo PRISA9 , fundado em 1976, momento em que a Espanha passava por uma transição do regime político ditatorial conhecido como "franquismo" (do governo do general Francisco Franco, de 1939 a 1976) para o seu período democrático. (ALMEIDA, 2016; SANTOS \& VILLELA, 2018)

Barrere e Almeida (2017) contextualizam historicamente o jornal:

\begin{abstract}
Seus primeiros números foram publicados no mês de maio, em meados dos anos 70, dentro de um contexto sociopolítico importante no país, que foi a transição política para a democracia. Devido ao golpe de 23 de fevereiro de 1981, que consistiu em uma tentativa de golpe militar por um grupo de guardas comandado pelo tenente-coronel Antonio Tejero, o El país assumiu uma postura fortemente nacionalista e democrática, circunstância que o fez alcançar liderança na imprensa espanhola. O jornal tornou-se um diário global e independente, sendo pioneiro na adoção de critérios jornalísticos, que orientam as relações entre os membros da redação, leitores e dirigentes. Com sua sede em Madrid, o El País também conta com pontos de redação situados em Barcelona, Sevilha, Valencia, Santiago de Compostela, Bilbao e em outras cidades dos 45 países do mundo que abrangem sua cobertura jornalística, entre as quais São Paulo, no Brasil. (BARRERE \& ALMEIDA, 2017, p. 68)
\end{abstract}

Considerado como "[...] um jornal de relevância internacional" por Santos e Villela (2018, p. 2), o El País tem como característica seguir uma tendência "[...] europeísta e social-democrata, além de oferecer grande destaque a informações de âmbito internacional, cultura, política e economia." (ALMEIDA, 2016, p. 46). Ainda segundo Barrere e Almeida (2017, p. 68), "A aparição do El País na internet se deu em 1996, quando foi inaugurada a primeira edição digital do endereço eletrônico elpais.com, e no início dos anos 2000 o jornal optou pela migração de todas suas publicações ao sítio virtual". Atualmente, o jornal El País conta com 5 (cinco) edições: espanhola, catalã, americana, inglesa e brasileira (FREIRE \& FERNANDES, 2019).

9 Conforme Faria (2010, p.14), "[...] o Grupo Prisa é o maior conglomerado de comunicação na Espanha, dono de jornais, sites, televisões e rádios, além de ter negócios em Portugal, Brasil e Estados Unidos."

CSOnline - Revista Eletrônica de Ciências Sociais, Juiz de Fora, n. 31 (2020) 
O portal de notícias do El País Brasil iniciou suas operações em 26 de novembro de 2013 (ALMEIDA, 2016; ABIB, 2017; BARRERE \& ALMEIDA, 2017), com sua redação situada na cidade de São Paulo, publicando sua versão em português. Segundo Almeida (2016), foi devido ao crescimento excessivo de acesso do público brasileiro ao site espanhol durante os protestos de junho de 2013 em todo Brasil que "[...] motivou a criação de uma versão em português, denominada de El País Brasil." (ALMEIDA, 2016, p. 46). É interessante perceber, com esse detalhe histórico, o vínculo entre esporte e ideologia no próprio jornal em questão, isto é, o surgimento da versão brasileira do El País ocorre justamente no momento dos protestos generalizados - mas mais intensos em São Paulo - envolvendo críticas à realização e investimentos quanto à Copa do Mundo de Futebol de 2014 em várias capitais brasileiras.

Conforme Santos e Villela $(2018$, p. 3), a versão espanhola do El País é "[...] considerada um dos dez jornais mais lidos do mundo", enquanto a versão brasileira "[...] chegou a 6,5 milhões de leitores mensais na mesma data [setembro/2017)", segundo informações da Comscore. Os dados informados por Leal \& Johnson (2019, p. 18), também a partir das métricas da Comscore (2017) colocam o website El País Brasil como "[...] o segundo em tráfego mensal entre os sites internacionais de notícias no país", com "[...] 6,484 milhões de usuários únicos, logo atrás da britânica BBC News Brasil, com 6,977 milhões", dados de outubro de 2017.

Ainda segundo tais autores:

As métricas sinalizam que as operações do El País Brasil estão funcionando porque o jornal europeu é percebido pelo leitor como independente, plural em suas opiniões e socialmente responsável, portanto, uma alternativa à cobertura jornalística com baixa diversidade ideológica da mídia brasileira. O público da edição brasileira está concentrado nas regiões Sudeste e Sul (São Paulo, Rio de Janeiro, Minas Gerais, Paraná e Rio Grande do Sul) e é formado por empresários, intelectuais e jovens universitários. (LEAL \& JOHNSON, 2019, p. 19)

Há vários estudos que enfocam a versão espanhola do jornal El País, como: (a) pesquisa de Almeida (2016), que analisou as representações da identidade brasileira de acordo com o jornal espanhol durante a Copa do Mundo de 2014; (b) pesquisas que abordam quanto ao "jornalismo do desacontecimento" e a 
complexidade na narrativa da repórter e articulista Eliane Brum (ABIB, 2017; VIVAR \& ABIB, 2018); (c) estudos como o de Santos e Villela (2018) que analisam o discurso do El País e a produção de sentidos durante o projeto Redenção na Cracolândia em São Paulo; além de, (d) análises críticas de artigo de opinião publicado no El País referente às obras da Copa de 2014 no Brasil e as grandes manifestações de 2013 (BARRERE \& ALMEIDA, 2017).

Em relação ao El País Brasil, as pesquisas que encontramos são bastante recentes. Bittencourt (2020) investigou a construção da figura política de Jair Bolsonaro no referido jornal, em que se percebe que o veículo midiático posiciona-se no sentido de alertar os perigos da extrema-direita no Brasil. Também em relação a um contexto político de investigação no jornal El País Brasil, a pesquisa de Freire \& Fernandes (2019) procurou apresentar como a midiatização da fake news "kit gay" foi operada e repercutida em reportagens desse veículo, a partir dos conteúdos oriundos das redes sociais digitais, nos meses que antecederam as eleições de 2018 no Brasil. Já a investigação de Cabral \& Prado (2019) focou a questão de gênero e esporte analisando as reportagens do El País Brasil sobre a participação de mulheres nos Jogos Olímpicos do Rio de Janeiro (2016), identificando que o referido website reproduz, segundo os autores, machismo e misoginia, subjugando as mulheres no âmbito esportivo e ridicularizando seus corpos. Também o suicídio na sociedade contemporânea (GALON, 2018), discutido na mídia jornalística no ano de 2017; e de como a economia brasileira foi tratada no El País Brasil no primeiro semestre de 2017 (GHENO, 2017), são exemplos.

\section{Apresentando e discutindo as categorias formuladas a partir do EI País Brasil}

A seguir, apresentamos e refletimos sobre os 5 agrupamentos temáticos (Quadro 01) oriundos das 103 (cento e três) reportagens identificadas no El País Brasil na seção "Esportes" no período de janeiro de 2019 a fevereiro de 2020, os quais discutimos sob a perspectiva da concepção crítica da análise da ideologia (THOMPSON, 2011), compreendendo, basicamente, que os fenômenos ideológicos apresentam-se a partir das mais diversas formas simbólicas presentes nas sociedades, carregando significados que estruturam relações de poder. 
Quadro 01 - Agrupamentos temáticos ${ }^{10}$ das reportagens do El País Brasil

\begin{tabular}{|c|c|c|}
\hline Temática & Contexto & Recorrência \\
\hline Machismo & $\begin{array}{l}\text { Tematizam a naturalização do comportamento } \\
\text { machista de jogadores e abordam os direitos } \\
\text { das mulheres. }\end{array}$ & $\begin{array}{l}39 \\
\text { reportagens }\end{array}$ \\
\hline Política e Fascismo & $\begin{array}{l}\text { Tratam especificamente sobre posições } \\
\text { políticas de jogadores, também evidenciando } \\
\text { questões fascistas em contextos históricos. }\end{array}$ & $\begin{array}{l}20 \\
\text { reportagens }\end{array}$ \\
\hline Racismo & $\begin{array}{l}\text { Abordam questões raciais envolvendo } \\
\text { jogadores, árbitros, torcidas, clubes, enfim, o } \\
\text { campo esportivo em geral. }\end{array}$ & $\begin{array}{l}16 \\
\text { reportagens }\end{array}$ \\
\hline $\begin{array}{l}\text { Mercadorização e } \\
\text { Tecnologias }\end{array}$ & $\begin{array}{l}\text { Abordam vínculos entre esporte e mercado, } \\
\text { além da discussão quanto ao VAR (árbitro de } \\
\text { vídeo). }\end{array}$ & $\begin{array}{l}16 \\
\text { reportagens }\end{array}$ \\
\hline $\begin{array}{l}\text { Homofobia e } \\
\text { Preconceitos/assédio } \\
\text { sexual }\end{array}$ & $\begin{array}{l}\text { Tratam de alguns casos de homofobia e } \\
\text { preconceito sexual envolvendo jogadores e } \\
\text { clubes. }\end{array}$ & $\begin{array}{l}12 \\
\text { reportagens }\end{array}$ \\
\hline
\end{tabular}

Fonte: Os autores.

Quando analisamos produções midiáticas não podemos deixar de considerar que é no contexto histórico e ideológico que os discursos se estabelecem. Do mesmo modo, quanto ao campo

10 A organização dos cinco temas não ocorreu de forma aleatória, mas sim pela quantidade das reportagens identificadas, em ordem decrescente de recorrência, sendo que o principal critério de inclusão em um ou outro tema ocorreu principalmente pela chamada no título da reportagem, embora na apresentação e na análise de cada um dos temas, trazemos exemplos de algumas reportagens mais icônicas relacionadas à temática. Apesar da separação dos cinco temas, é importante considerar que há uma relação de interdependência e de complementariedade entre eles.

CSOnline - Revista Eletrônica de Ciências Sociais, Juiz de Fora, n. 31 (2020) 
esportivo, como nos lembra Sanfelice (2018), devemos considerálo como:

[...] um lugar complexo, de cruzamento de múltiplas agendas, em que não podemos considerar como integrantes do espetáculo somente os competidores, mas os espectadores, as famílias dos competidores, os gestores, os patrocinadores, enfim, os medias. (SANFELICE, 2018, p. 18, grifos nossos)

No conjunto das reportagens identificadas e analisadas, é possível visualizarmos um entrecruzamento de discursos. Campos que se atravessam e conflituam somam-se ao "trivial" da produção, cobertura e veiculação midiática sobre esporte: há a cobertura das competições (pautando início das mesmas, abordando jogos, trazendo curiosidades, apresentando e repercutindo resultados), a habitual ênfase nos principais atletas (homens, principalmente, como os jogadores de futebol Neymar, Messi, Cristiano Ronaldo, mas também atletas de outras modalidades); assim como atual discussão sobre tecnologia e esporte, notadamente o uso no futebol do VAR (árbitro de vídeo) e a polêmica suscitada.

Seguindo a tendência do jornalismo nacional, o futebol é o principal motor dos temas tratados nas reportagens. Em geral, o agrupamento temático aqui apresentado resulta de reportagens e crônicas esportivas que correspondem ao cânone jornalístico e seu papel de repercutir os esportes e eventos cujos interesses econômicos e culturais são mais fortes. Do mesmo modo, é acionando o modelo discursivo padrão, que usa os "ídolos esportivos", sucesso, vitória, conquista como pontos sobre os quais - resto transita. Tais aspectos são importantes para que se compreenda as limitações dos discursos produzidos e suas implicações ideológicas.

Passemos, então, à apresentação e breve análise de cada um dos agrupamentos temáticos:

\section{- Machismo}

No agrupamento temático que denominamos "machismo", constam 39 reportagens que, sob maneiras variadas, tematizaram a naturalização do comportamento machista de jogadores, além de matérias que abordaram direitos das mulheres, dando destaque a certos ineditismos (como o fato de uma mulher apitar pela primeira vez um jogo masculino da liga francesa; de jogos 
com recordes mundial de público para o futebol feminino; da Rede Globo transmitir todos os jogos da seleção feminina na Copa/2019; do Brasil pela primeira ter uma estrangeira comandando a seleção etc.) e ao contexto da realização da Copa do Mundo de Futebol Feminino na França em 2019 (explorando a visibilidade do evento para o futebol feminino e clamando por "igualdade"; falas emocionadas como da jogadora brasileira Marta pedindo apoio à seleção e da população que "abraçou" a seleção brasileira; bem como o destaque dado em algumas reportagens à seleção norteamericana, vencedora do torneio, e sua jogadora principal, Megan Rapinoe).

Considerado o número de reportagens, fica evidente que a tematização de questões que envolvem práticas machistas e que procuram mobilizar a atenção em relação aos direitos das mulheres no campo esportivo demonstra um aspecto hegemônico de nossa cultura. Por outro lado, mesmo narrativas que se colocam em prol de uma suposta "igualdade" de condições entre homens e mulheres obscurecem práticas de violência simbólica e de naturalizações, conforme aprendemos com Thompson (2011) quando nos dedicamos a estudar ideologia criticamente. Tal aspecto se dá na medida em que é mediado pelo sucesso dos atletas, pela vitória pessoal, que o direito ao discurso contra o machismo se configura.

Conforme estudo de Cabral \& Prado (2019), estudando o site do El País Brasil, perceberam "[...] que a representação da mídia sobre a participação de mulheres atletas nos Jogos Olímpicos no Brasil (re)produz o machismo e a misoginia", considerando que geralmente as mulheres são subjugadas ao se ridicularizar seus corpos colocando-os à sombra dos corpos masculinos. Segundo tais autores, "[...] existem diversas maneiras de se reproduzir 0 machismo: violência física, verbal, psicológica etc." (CABRAL \& PRADO, 2019). Outro modo, é aviltando os "corpos fracos", dando poder e voz apenas àqueles que vencem.

Se o universo esportivo, de modo geral, é um universo masculino, a dominação neste campo - esportivo - é masculina. Assim, o envolvimento das mulheres, mesmo em pleno século XXI, ainda se mostra com dificuldades de acesso, desigualdades estruturais, proibições, comparações etc. Visualizamos nos títulos das reportagens e no conteúdo das mesmas um discurso supostamente "politicamente correto", dando destaque às 
conquistas femininas no universo esportivo, principalmente no futebol. Reiteradamente há denúncias de que as mulheres não têm as mesmas possibilidades ofertadas aos homens (salários, patrocínios, visibilidade, reconhecimento, acesso a estádios na condição de torcedoras no Irã e na Arábia Saudita, "condições iguais" de acesso aos setores diversos do contexto esportivo etc.).

Outra questão abordada e que, num primeiro olhar, pode gerar uma percepção de posicionamento progressista do El País Brasil em relação à participação das mulheres no futebol/esporte, são os recorrentes discursos que atribuem a uma maior exposição do futebol feminino na televisão aberta, e, com isso, uma "grande transformação" do amadorismo do futebol feminino no "grande produto" que é o futebol masculino mundial. E assim, alia-se a esse discurso marcas esportivas mundiais, que "investem" no futebol feminino para que o mesmo passe a ser reconhecido pelo público como ocorre em relação aos homens - a adequação também do esporte feminino aos cânones da mercadorização esportiva (PIRES, 1998).

Além disso, poderíamos dizer que se explicita um discurso "romântico" em relação aos "avanços" das mulheres no campo esportivo, em relação à sua representatividade e consolidação. Percebe-se que muitos desses discursos ocorrem em períodos de grandes eventos esportivos - Copa do Mundo de Futebol e Jogos Olímpicos -, aproveitando-se de uma certa efemeridade da exposição das atletas que, como se constata de modo geral depois desses megaeventos esportivos, não repercute em avanços como igualdade salarial, igualdade de competições, igualdade de visibilidade etc. Temos aí, portanto, segundo aprendemos com a concepção crítica de análise da ideologia de Thompson (2011), elementos legitimadores, elementos dissimuladores, unificadores, fragmentadores e reificadores.

Ainda em relação a esse agrupamento temático, incluímos reportagens que exploraram práticas machistas naturalizadas: em relação ao álbum de figurinhas da Copa (uma reportagem que comentou o fato do álbum feminino ser menor e menos divulgado que o masculino; outra reportagem que mostrou reações machistas ao álbum); episódios de violência doméstica de atletas masculinos; e o episódio do "caso Neymar", acusado de estupro, com intimidade exposta e repercussões machistas.

\section{- Política e Fascismo}


$\mathrm{Na}$ temática "política e fascismo" foram encontradas 20 reportagens que, sob alguma forma, tematizaram questões políticas envolvendo o esporte ou relações entre poder e esporte, além de algumas poucas reportagens que se dedicaram a apresentar situações que envolveram comportamentos ditos como "nazistas" ou jogadores que se colocaram como resistência em momentos históricos, seja na Itália ou no Chile, ou mesmo em relação ao golpe militar no Brasil.

O fragmento da matéria "Quando o oportunismo político se apropria da festa do futebol" nos propõe o problema:

\begin{abstract}
Quem diz que esporte e política não se misturam provavelmente nunca aprofundou $\circ$ olhar para $\circ$ jogo de bastidores nem atentou para os cerimoniais de premiação dos times campeões. Usar o futebol como plataforma de exibicionismo é prática antiga dos políticos, assim como clubes e federações insistem em atrair autoridades à solenidade de medalhas e troféus. Porém, o que se vê ultimamente nos desfechos de campeonatos pelo país é um festival de apropriação do protagonismo por parte de representantes públicos que jamais derramaram uma gota de suor no gramado, mas, com faro oportunista de dar inveja a goleador, ofuscam o momento sagrado dos jogadores. (EL PAís BRASIL, Quando o oportunismo político se apropria da festa do futebol ${ }^{11}$ ).
\end{abstract}

Assim como se explicita na narrativa jornalística, as relações entre esporte e política, relações recorrentemente negadas por comentaristas, especialistas esportivos e personagens do campo midiático, geram controvérsias tanto no campo jornalístico quanto no esportivo. Se considerarmos a aparição e veiculação de reportagens que se debruçam nas temáticas da política e do poder em suas conexões com o fenômeno esportivo (quando o referido veículo midiático retrata jogadores que se envolvem com escolhas políticas; situações que envolvem a "bancada de bola" no Congresso Nacional brasileiro; questões clubísticas e política partidária; nepotismo; corrupção ou mesmo fatos históricos sobre esporte e poder etc.), fica evidente que o El País Brasil, ao abordálas, também assume uma postura política.

Tal postura, quando pensamos em relação às modalidades de produção simbólica daquilo que seria a ideologia em Thompson (2011), a pouca profundidade dada às reportagens; a dificuldade

11 Disponível em: https://brasil.elpais.com/brasil/2019/04/23/deportes/1555979200_847108.html Acesso em: 27 abr. 2020. 
em ampliar a discussão para além das relações políticas que sempre terminam nos "cartolas"; a fragmentação dada ao conjunto de reportagens e a quase naturalização (reificação) de um "mantra" que não avança sobre esporte, política e corrupção, sem ir a fundo nessas questões, evidencia um discurso ideológico também do El País Brasil.

Um esforço de neutralidade ideológica transparece quando são veiculadas reportagens que expõem fascismo e nazismo, ao mesmo tempo, embora em menor número, quando tematiza personagens do universo esportivo que são declaradamente do espectro político da esquerda, como os argentinos Maradona e Sampaoli, ou mesmo pelo seu posicionamento crítico e contrário em relação à extrema-direita brasileira. Aqui, a objetividade jornalística joga com a complexidade da política, depositando no outro, no agente social, a responsabilidade de suas posições.

\section{- Racismo}

O racismo, temática identificada em 16 (dezesseis) reportagens, compreendeu conteúdos que abordaram questões raciais envolvendo atletas (homens e mulheres), árbitros, torcidas e clubes. Em geral, nas reportagens são identificadas a denúncia de atos racistas no contexto futebolístico, com casos específicos de alguns jogadores em situações de jogo, principalmente na Europa e certa "indignação" em relação à recorrência dos atos, como podemos ver na reportagem "Convivência com o racismo, uma regra não escrita do futebol":

O futebol, infelizmente, não reproduz nada de novo. Do Brasil a Portugal, a convivência pacífica com o racismo tem sido assimilada como norma ao longo de décadas. E os sinais estão por toda parte. [...]. O futebol, porém, ao contrário de muitos espaços, impulsiona negros a posições de protagonismo. Por consequência, os expõe à fúria incontida dos racistas. [...]

Enfrentar o racismo é uma missão social, coletiva e civilizatória, não um fardo que apenas as pessoas e personalidades negras devem carregar. Nesse sentido, é fundamental que a ação seja transformadora, especialmente em uma plataforma de longo alcance como o esporte. [...]. (EL PAÍs BRASIL, Convivência com o racismo, uma regra não escrita do futebol ${ }^{12}$ )

12 Disponível em: https://brasil.elpais.com/esportes/2020-02-17/conivencia-com-o-racismo-umaregra-nao-escrita-do-futebol.html. Acesso em: 27 abr. 2020. 
Na reportagem "Lucas Santos: 'Saí da favela, mas não posso ficar alienado enquanto matam negros e pobres'", aborda-se quanto ao jogador negro e oriundo de favela carioca, revelação do time do Vasco na Copa São Paulo de Juniores (maior torneio de base brasileiro), que foi convocado para a seleção brasileira e recentemente transferiu-se para O CSKA da Rússia. O atleta comenta dificuldades enfrentadas por ser negro e de origem pobre, aborda questões políticas e relata influência de ativistas negros.

Consta também outra reportagem que trata especificamente do caso de racismo ocorrido com o jogador de futebol Taison, que atua no Shakhtar Donetsk (Ucrânia), que sofreu insultos racistas dos torcedores do Dínamo de Kiev. O atleta revoltou-se com a torcida após sofrer uma falta e voltando-se a ela chutou a bola, fazendo um gesto obsceno naquela direção. Embora o árbitro tenha paralisado o jogo para que os cânticos racistas parassem, quando reiniciou o jogo, expulsou o jogador brasileiro pelas reações que o mesmo teve às agressões sofridas, com Taison saindo chorando do jogo. O texto expõe a situação, ao mesmo tempo que enfatiza a luta dos "craques brancos" no combate ao racismo:

A expulsão de Taison depois de responder aos insultos racistas apenas escancara como cartolas brancos ditam regras que condenam jogadores negros à convivência pacífica com o racismo. O futebol reproduz o apartheid em forma de fair play. E ainda há quem exija heroísmo solitário dos negros... Seria importante que um craque branco se manifestasse com veemência diante de um companheiro ofendido por racistas. [...] Ou um treinador branco adotar discurso tão firme como o do Roger Machado. Isso é o que devemos cobrar, não apenas atitudes de quem sofre diariamente com o racismo.

\section{[...]}

Nesse aspecto, Taison se revela maior que Messi e outras estrelas do esporte que não se sentem tocadas pelo racismo. Maior que as entidades da bola que relativizam ofensas racistas. O futebol é muito mais que um jogo. Justamente por isso, seus grandes ídolos deveriam ser muito mais que meros jogadores. Taison, ao contrário da profecia de uma década atrás, não entrou para o panteão dos supercraques. Mas, pela demonstração de caráter ao denunciar os racistas, atingiu um estágio como cidadão que poucos deles 
conseguem igualar. (EL PAÍS BRASIL, Taison se impõe contra o racismo e mostra que é maior que Messi ${ }^{13}$ )

Quando analisamos o racismo e seu viés ideológico, ao menos especificamente nestes casos, percebemos que o discurso do El País Brasil enfatiza o aspecto particular dos casos, embora mencione que são recorrentes no contexto esportivo, ocultando que essa problemática que envolve a sociedade é algo estrutural, ou seja, explicita-se o elemento que Thompson (2011) nos fala quanto à dissimulação presente nos discursos ideológicos. Há, também, o elemento de unificação do discurso ideológico, ou seja, reitera-se o problema, mas não se consegue pensálo/abordá-lo para além da esfera do campo esportivo (quando, no máximo, uma posição do clube), portanto, reificase/naturaliza-se o problema, principalmente quando ocorre 0 discurso de que o racismo no futebol ocorre porque os negros se transformam em protagonistas no futebol (pelo seu talento e pelas suas performances).

Também observamos reportagens que tratam da questão do racismo em relação a clubes brasileiros, como no caso do Vasco da Gama, por ser pioneiro em aceitar os negros no futebol; no caso do Grêmio a abolição de termos racistas nos cânticos de sua torcida; da Ponte Preta, que teve um inédito presidente negro; e em relação ao Santos, uma reportagem que mencionou que é - clube dos ídolos negros, e outra que expôs a cobrança da torcida santista pelo vazamento de um áudio racista em que um conselheiro do clube comenta que "todo pardo é mau-caráter". E uma outra que abordou sobre os dois únicos técnicos negros do Campeonato Brasileiro em 2019, além de uma reportagem que considerou a questão indígena, uma ação do clube Bahia.

\section{- Mercadorização e Tecnologias}

Na temática que envolveu mercadorização e tecnologias, observamos e analisamos 16 (dezesseis) reportagens no El País Brasil que pautaram vínculos entre esporte e mercado, além de identificarmos uma pequena discussão envolvendo o VAR (árbitro de vídeo).

Dentre o conjunto de reportagens aglutinadas com a temática em tela, a intitulada "Havan no Vasco, a história em jogo por um

13 Disponível em: https://brasil.elpais.com/brasil/2019/11/11/deportes/1573487854_972621.html.

Acesso em: 27 abr. 2020. 
patrocínio" revela explicitamente tais relações entre mercado e esporte:

$\mathrm{Na}$ última terça-feira, o presidente vascaíno Alexandre Campello visitou a sede da Havan, em Santa Catarina, para tratar com Luciano Hang de um possível patrocínio. O empresário se interessou em expor sua marca no uniforme do time carioca após um grupo de torcedores subir a hashtag\#HavanNoVasco. No mundo ideal, instituições esportivas rejeitariam investimentos de empresas com as quais não partilham valores. No sistema mercantilista do futebol, porém, dinheiro está acima da própria história dos clubes. A aproximação entre Vasco e Havan se encaixa nesse contexto.

[...]

O futebol, como outras atividades, obedece à lógica impositiva das relações econômicas, em que dinheiro no bolso não costuma ver cara nem coração. Mas o Vasco, como outros times que simbolizam a paixão pelo esporte mais popular do país, carrega o valor intangivel de milhões de torcedores representados por suas cores. Princípios são inegociáveis. Independentemente do desfecho das tratativas com a Havan, o clube sempre deve prevalecer sobre os caprichos de investidores e empresários. (EL PAÍS BRASIL, Havan no Vasco, a história em jogo por um patrocínio ${ }^{14}$ )

Empresário, presidente, patrocínio, marca, uniforme, investimentos, empresas, sistema mercantilista, dinheiro, aproximação, relações econômicas, investidores, paixão... conjunto de palavras que explicitam toda lógica mercadológica já bastante conhecida do fenômeno esportivo, em que o esporte se torna uma mercadoria simbólica. Pires (1998) argumenta que em relação à mercadorização esportiva ocorre "[...] um aumento no volume do capital empregado para financiar o esporte, o que requer um retorno ampliado (mais lucro) aos proprietários do capital investido, empresários que se utilizam do esporte como mercado e vetor de divulgação dos seus produtos e serviços." (PIRES, 1998, p. 31).

Também encontramos reportagem que comenta 0 caso específico de fracasso do modelo clube-empresa; outra que aborda a gentrificação do futebol; sobre jogadores presos por manipular resultados na elite do futebol espanhol; matéria sobre a possibilidade de ascensão social pela via do futebol; além de

14 Disponível em: https://brasil.elpais.com/brasil/2019/12/11/deportes/1576098811_301346.html. Acesso em: 27 abr. 2020. 
outra que procura compreender por que os clubes brasileiros se endividam tanto. Acrescentamos a esta temática outras 8 (oito) reportagens que deram ênfase à tragédia (cobertura, repercussões, implicações - em que cifras econômicas costumam aparecer nas narrativas) do incêndio no Centro de Treinamento do Flamengo que vitimou 10 jovens atletas em fevereiro de 2019.

A discussão bastante atual - e polêmica - que envolve a tecnologia (e seu fetiche) do VAR, o árbitro de vídeo, apareceu em duas reportagens. Numa reportagem em junho/2019, pouco tempo antes de iniciar a Copa do Mundo de Futebol Feminino, intitulada "Futebol feminino descobre O VAR", é perceptível identificarmos aspectos de legitimação (com discursos lógicos e encadeados), de dissimulação (ocultando os motivos da quase inexistência de mulheres nos setores esportivos) e, principalmente, de reificação, naturalizando o uso tecnológico como "salvador" e "benfeitor" dos contextos internos das competições esportivas, numa perspectiva de encantamento acrítico. Vejamos:

Descobrir o VAR em uma Copa do Mundo. As 24 seleções também jogarão diante da tela. O torneio que acontece na França é a primeira competição feminina que testará a videoarbitragem. [...]

[...]

April Heinrichs, diretora do Grupo de Estudos Técnicos da FIFA nesta Copa do Mundo [...], também analisa o impacto do VAR: "Como regra geral, em cada Copa entre cinco e 10 gols são duvidosos. Agora acertaremos em todos. Por outro lado, e embora não seja habitual no futebol feminino fingir ou simular em alguma jogada, a honestidade das jogadoras prevalecerá com O VAR. É um sistema que incentiva o espírito esportivo". Ela também aponta para uma mudança no padrão de jogo que pode afetar a arbitragem: "Acredito esta que será a Copa do Mundo feminina mais rápida da história nas transições da defesa para o ataque e na passagem da posse à perda da bola. Mais razões para contar a ajuda do VAR". (EL PAÍS BRASIL, Futebol feminino descobre o VAR ${ }^{15}$ )

Já a segunda reportagem sobre o VAR, publicada em novembro de 2019, "O VAR veio para arruinar o esporte mais precioso de todos os tempos", como podemos identificar pelo seu título, tratase de uma entrevista do El País Brasil com o jornalista e

15 Disponível em: https://brasil.elpais.com/brasil/2019/06/06/deportes/1559842067_070072.html. Acesso em: 27 abr. 2020.

CSOnline - Revista Eletrônica de Ciências Sociais, Juiz de Fora, n. 31 (2020) 
comentarista esportivo Arnaldo Ribeiro, em que, em uma de suas respostas, sentencia:

[...] O VAR amplifica, para o mal, a interferência da arbitragem no jogo de futebol, que é o esporte mais sagrado de todos os tempos, sob a égide da justiça, que é bem discutível. Ele aumenta o número de intervenções, interrompe o jogo, entra em lances interpretativos que não são capazes de serem elucidados. O VAR nasceu errado. As tentativas de adoção dele com parcimônia em ligas mais estruturadas, como a Premier League, talvez suavizem, mas ao mesmo tempo evidenciam os limites do árbitro de vídeo. Se o VAR veio para ficar, ele veio para arruinar o esporte mais precioso de todos os tempos. (EL PAÍS BRASIL, "O VAR veio para arruinar $O$ esporte mais precioso de todos os tempos"16)

Há todo um discurso conservador em relação à defesa de um "futebol puro", "justo" e "mágico", que não apresenta limitações, incongruências e injustiças, como uma modalidade que não pode ser "tocada" porque não pode ser alterada. Embora seja uma entrevista, as respostas do sujeito entrevistado reforçam discursos ideológicos com elementos legitimadores (do futebol e sua meritocracia), com elementos dissimuladores (que ocultam a dominação do capital econômico diante do capital futebolístico), a unificação e a fragmentação, e, principalmente, o elemento de reificação, naturalizando o conservadorismo do futebol.

\section{- Homofobia e Preconceitos/assédio sexual}

Identificamos 12 (doze) reportagens que tematizaram episódios e discussões em torno da homofobia e de preconceitos e assédio sexual envolvendo jogadores e clubes. Uma das reportagens mais explícitas que pautou a homofobia no futebol brasileiro apresentou o jogador Flávio, do Bahia, ao se encorajar e se orgulhar em vestir a camisa cuja numeração "assusta" a maioria dos jogadores homens, a de número 24, um tabu historicamente associado à homossexualidade pela sua relação com o número no jogo do bicho.

Assim, na reportagem de Breiller Pires, "'Vesti a camisa 24 com muito orgulho', diz jogador do Bahia após usar 'número proibido' pela homofobia" é possível identificarmos uma construção simbólica (discursiva) que confronta uma prática cultural

16 Disponível em: https://brasil.elpais.com/brasil/2019/10/07/deportes/1570476377_375331.html.

Acesso em: 27 abr. 2020. 
sedimentada historicamente, ou seja, uma depreciação à masculinidade simplesmente pelo uso de uma numeração.

Ao divulgar a ação, o departamento de ações afirmativas do clube lembra que o 24 é tratado como "número proibido" e "gatilho para a homofobia" não apenas no contexto do esporte, citando, por exemplo, a manifestação implícita de preconceito no Senado, que excluiu os algarismos da numeração dos gabinetes entre 2015 e 2019.

Flávio, um dos líderes do elenco do Bahia, dono da camisa 5, planeja utilizar a 24 no restante da temporada. "Número de camisa não afeta em nada minha masculinidade nem meu desempenho dentro de campo. Infelizmente, existe essa conotação negativa em torno do 24. Mas me deu sorte, saímos com a vitória e quero que seja meu número daqui pra frente." [...]

(EL PAÍS BRASIL, "Vesti a camisa 24 com muito orgulho", diz jogador do Bahia após usar 'número proibido' pela homofobia ${ }^{17}$ )

Identificamos, neste caso em específico, um discurso progressista que procura deslegitimar uma prática vinculada a uma masculinidade no universo esportivo, ao mesmo tempo expõe uma certa desnaturalização dessa mesma prática. Apesar de visualizarmos uma posição crítica do El País Brasil, cuja narrativa procura transformar práticas discursivas (jornalísticas) em espaços de respeito às diversidades a partir de fatos comuns do cotidiano do contexto esportivo - permeado de discursos legitimadores, unificadores e reificadores, quando retomamos os elementos que estruturam um discurso ideológico dominante - consideramos que não há como o El País Brasil não mostrar o discurso do tempo presente, não sendo mais possível defender práticas conservadoras como o fato de não vestir uma camiseta com o número 24 porque está associado a uma suposta homossexualidade.

Entretanto, evidencia-se uma superficialidade discursiva de não avançar para além da explanação do problema e da exemplificação do caso: depois deste caso, passou a ser comum os jogadores vestirem a camiseta de número 24? Nos corredores do senado federal, passou a ter a sala de número 24? Verificamos, então, certas limitações e questões que embora apontem

17 Disponível em: https://brasil.elpais.com/esportes/2020-01-30/vesti-a-camisa-24-com-muito-

orgulho-diz-jogador-do-bahia-apos-usar-numero-proibido-pela-homofobia.html. Acesso em: 27 abr. 2020.

CSOnline - Revista Eletrônica de Ciências Sociais, Juiz de Fora, n. 31 (2020) 
aspectos discursivos progressistas, no plano do cotidiano não avançam tanto, há uma certa manutenção da ordem.

Outro exemplo de reportagem do El País Brasil em relação à homofobia é o texto também de Breiller Pires, "Com homofobia não tem jogo", em que o jornalista aponta o fato inédito ocorrido no Campeonato Brasileiro de Futebol em 2019:

\begin{abstract}
Neste domingo [27 de agosto de 2019], o futebol brasileiro, pródigo em polêmicas fugazes que se repetem a cada fim semana, presenciou um fato inédito em sua história. Aos 19 minutos do segundo tempo, o árbitro Anderson Daronco interrompeu o duelo entre Vasco e São Paulo, quando parte da torcida vascaína cantava "time de viado" nas arquibancadas de São Januário para provocar os rivais. Foi a primeira vez que a arbitragem paralisou um jogo por causa de cânticos homofóbicos. Após serem notificados, jogadores e o técnico da equipe carioca, Vanderlei Luxemburgo, acenaram do campo para que os torcedores não entoassem mais os gritos ofensivos. (EL PAÍs BRASIL, Com homofobia não tem jogo ${ }^{18}$ )
\end{abstract}

Nesse mesmo movimento que se opõe às práticas homofóbicas no futebol, consta também textos como "A resposta histórica do Fluminense à homofobia", "Um manifesto tardio, porém necessário, do São Paulo contra a homofobia"; além de reportagens que expõem as jogadoras de futebol, tanto da seleção brasileira como a grande estrela do futebol feminino mundial, Megan Rapinoe, dos EUA.

Quanto aos preconceitos e questões envolvendo assédio sexual, foram produzidas e veiculadas reportagens como "Atletas fazem de 2019 o ano da luta contra o preconceito", "Os 'times do povo' que rejeitam o povo", "Manchester City indenizará jogadores que foram vítimas de abuso sexual no clube", "Negar favela é insulto à vocação popular do Flamengo", e também "'Malhação' joga luz sobre o abuso sexual no futebol".

Observando tais reportagens e a temática da homofobia no esporte, retomamos a pesquisa de Leal $\varepsilon$ Johnson (2019), para os quais há um conflito entre a percepção de quem lê o El País Brasil e o próprio autoposicionamento do referido veículo. Ou seja, por termos, no Brasil, uma indústria cultural tão forte e homogênea ideologicamente (FSP, Globo, Estadão etc.), quando acessamos e

18 Disponível em: https://brasil.elpais.com/brasil/2019/08/26/deportes/1566852465_773027.html. Acesso em: 27 abr. 2020.

CSOnline - Revista Eletrônica de Ciências Sociais, Juiz de Fora, n. 31 (2020) 
nos informamos por um outro periódico de espectro de centro, como se considera o El País Brasil, a impressão que temos é que é algo muito progressista, como se houvesse uma "outra ideologia", confundindo-nos a ponto de pensarmos que a ideologia seja "neutra".

\section{Considerações finais}

Horkheimer e Adorno (1985), ao descreverem o funcionamento do que chamaram de "Indústria Cultural", argumentaram sobre o caráter ideológico da produção da cultura em modelo fordista. Serialização, padronização, repetição do sempre o mesmo serviriam tanto para produzir carros, como filmes ou notícias. Realizada a produção simbólica nos padrões da produção industrial, seria necessário compreender o caráter de dominação de tal processo. A pergunta, já clássica, era como as pessoas poderiam agir contra seus próprios interesses.

A noção de ideologia como falsa consciência grassava, mas não foi esse o caminho seguido pelos autores. Em sua análise da sociedade, perceberam que ideologia e realidade se confundiam e era preciso entender as forças postas em jogo naquele momento histórico. É com a análise da indústria cultural que algumas respostas se apresentaram e que aqui vão formar os argumentos que consideramos necessários para compreender 0 papel ideológico do El País Brasil apesar de sua capa progressista, deixado de lado seu evidente interesse econômico e desejo de lucro.

Muito sucintamente, quando o periódico lança mão dos grandes atletas ou eventos excepcionais, o que ocorre na maior parte das reportagens, sobre os quais temos acesso apenas como espectadores/consumidores, cria 0 efeito de identificação descrito por Horkheimer e Adorno (1985) quando trataram do cinema. Assim como a mocinha dos filmes, que deve ser ao mesmo tempo inatingível e parecer com todas as mulheres, provocando o efeito de passividade diante de tal figura, o modo de articulação de notícias apoiada em ídolos esportivos têm efeito semelhante. Identificação e mímeses operam no sentido de, ao confirmarem a cumplicidade, agirem no sentido de aniquilar $o$ 
ego, produzindo a passividade necessária à imobilidade de ação que estrutura o poder. O particular dissolve-se no universal ${ }^{19}$.

Por outro lado, o periódico acaba por reforçar uma das formas de dominação que sustentam o capitalismo tardio, qual seja, a meritocracia. As reportagens fortalecem os efeitos de dominação na medida em que aqueles que falam, ou dos quais se fala, tem papel de destaque na esfera esportiva, portanto no espaço social, reproduzindo a hierarquia social mesmo que através de posições que, no Brasil, soam progressistas. É na identificação passiva com a mocinha que a dona de casa se conforma com sua vida, assim também se dá com os ídolos esportivos. A Indústria Cultural promete tudo, mas não entrega nada. Assim também o jornalismo: fala de tudo, mas não muda nada.

\section{Referências}

ABIB, Tayane Aidar. $O$ expediente argumentativo no jornalismo de Eliane Brum: análise das colunas ao El País Brasil. CONGRESSO BRASILEIRO DE CIÊNCIAS DA COMUNICAÇÃO, 40., 2017, Curitiba/PR. Anais... Curitiba/PR: Intercom, 2017. 16 p. Disponível em: http://portalintercom.org.br/anais/nacional2017/resumos/R120333-1.pdf. Acesso em: 22 abr. 2020.

ALMEIDA, Paulo Henrique Soares de. Brasil e o olhar estrangeiro na Copa do Mundo: análise das narrativas do El País. REB - Revista de Estudios Brasileños, $v$. 3 , n. 5, $2^{\circ}$ sem. 2016, p. 42-54. Disponível em: https://dialnet.unirioja.es/servlet/articulo?codigo=5683355. Acesso em: 22 abr. 2020.

BARRERE, Luana Lisboa; ALMEIDA, Julia Maria Costa de. Uma análise discursiva crítica das representações do Brasil e do brasileiro no discurso do jornal El País. Miguilim - Revista Eletrônica do Netlli, Crato/CE, v. 6, n. 1, p. 58-81, jan./abr. 2017.

http://periodicos.urca.br/ois/index.php/MigREN/article/view/1278. Acesso: 23 abr. 2020.

BETTI, Mauro. Janela de vidro: esporte, televisão e educação física. Campinas: Papirus, 1998.

BITTENCOURT, Maria Clara Aquino. A construção da figura política de Bolsonaro no El País. um exercício metodológico para análise sobre produção de sentido no jornalismo. Galaxia, São Paulo, n. 43, jan./abr. 2020, p. 168-187. Disponível em: http://www.scielo.br/scielo.php?script=sci_arttextepid=\$1982-25532020000100168. Acesso: 23 abr. 2020.

CABRAL, Vitória Teixeira; PRADO, Vagner Matias do. Gênero e esporte: análise de reportagens sobre a participação de mulheres nos Jogos Olímpicos do Rio

19 Para saber sobre a relação entre teoria crítica e psicanálise, ver Rouanet (1989). 
de Janeiro. Arquivos em Movimento, Rio de Janeiro, v. 15, n. 15, jan./jul. 2019, p. 169-188.

CUNHA JUNIOR, C.F. da; MELO, V.A. de. Homossexualidade, educação física e esporte: primeiras aproximações. Movimento, ano III, n. 5, p. 18-24, 1996/2. Disponível em: http://seer.ufrgs.br/Movimento/article/view/2229/937 Acesso em: 10 abr. 2020.

ECO, Umberto. A falação esportiva. In: ECO, Umberto. Viagem na irrealidade cotidiana. Rio de Janeiro: Nova Fronteira, 1984, p. 220-226.

FARIA, Juliana Gomes de. Brasil: uma visão da imprensa espanhola sobre o país: como o jornal espanhol El País cobre o Brasil. 2010. 42 f. TCC (Graduação) Curso de Bacharel em Comunicação Social com Habilitação em Jornalismo, Faculdade de Tecnologia e Ciências Aplicadas, Centro Universitário de Braślia UNICEUB, Brasília/DF, 2010

FREIRE, Débora; FERNANDES, David. Midiatização nas redes sociais digitais como valor-notícia: o ingresso da fake News 'kit gay' na pauta do El País. SEMINÁRIO INTERNACIONAL DE PESQUISAS EM MIDIATIZAÇÃO E PROCESSOS SOCIAIS, 3., 2019, São Leopoldo. Anais... São Leopoldo/RS: PPGCC-Unisinos, 2019. 20p. Disponível em: https://midiaticom.org/anais/index.php/seminario-midiatizacaoartigos/article/download/260/254. Acesso em: 23 abr. 2020.

GALON, Tanyse. Abordagem jornalística do tema suicídio na sociedade contemporânea. Núcleo de Pesquisa em Comunicação Social da UNAERP, Ribeirão Preto/SP, n. 9, jun. 2018, p. 92-111. Disponível em: http://revistas.unaerp.br/inrevista/article/view/1391. Acesso: 23 abr. 2020.

GHENO, Nícholas Nicolau. A economia brasileira no Portal El País Brasil. uma análise de conteúdo do primeiro semestre de 2017. 2017. 147 f. TCC (Graduação) - Curso de Jornalismo, Faculdade de Biblioteconomia e Comunicação, Universidade Federal do Rio Grande do Sul - UFRGS, Porto Alegre/RS, 2017.

GIL, Antônio Carlos. Como elaborar projetos de pesquisa. $3^{a}$ ed. São Paulo: Atlas, 1996.

HORKHEIMER, M.; ADORNO, T. Dialética do Esclarecimento: fragmentos filosóficos. Rio de Janeiro: Zahar, 1985.

LEAL, Paulo Roberto Figueira; JOHNSON, Telma Sueli Pinto. O jornalismo da edição brasileira do El País no contexto da oligopolização midiática: dissonâncias entre percepção do público e autoposicionamento. Líbero Revista Eletrônica do Programa de Mestrado em Comunicação da Faculdade Cásper Líbero, ano XXII, n. 43, jan./jun. 2019, p. 14-28.

PIRES, G. De L. Breve introdução ao estudo dos processos de apropriação social do fenômeno esporte. Revista da Educação Física UEM, vol. 9, n. 1. p. 25-34, 1998.

ROUANET, Sérgio P. Teoria Crítica e Psicanálise. Rio de janeiro: Tempo Brasileiro, 1989.

ROUDINESCO, E.; PLON, M. Dicionário de Psicanálise. Rio de Janeiro: Jorge Zahar Editor, 1998. 
SANFELICE, Gustavo Roese. Processos midiáticos no campo esportivo. Curitiba: Appris Editora, 2018.

SANTOS, Fabiane Almeida; VILLELA, Cícero Costa. O discurso do El País e a produção de sentidos durante o projeto Redenção na Cracolândia em 2017. CONGRESSO DE CIÊNCIAS DA COMUNICAÇÃO NA REGIÃO SUDESTE, 23., 2018, Belo Horizonte/MG. Anais... Belo Horizonte/MG: Intercom, 2018. 12 p. Disponível em: http://portalintercom.org.br/anais/sudeste2018/resumos/R63-0347-1.pdf. Acesso em: 22 abr. 2020.

THOMPSON, John B. Ideologia e cultura moderna: teoria social crítica na era dos meios de comunicação de massa. $9^{a}$ ed. Petrópolis: Vozes, 2011.

TRIVIÑOS, Augusto Nibaldo Silva. Introdução à pesquisa em ciências sociais - a pesquisa qualitativa em educação. São Paulo: Atlas, 1995.

VIVAR, Jesús Miguel Flores; ABIB, Tayane Aidar. O expediente da argumentação no jornalismo de Eliane Brum: análise de suas colunas ao El País Brasil. Comunicação \& Inovação, São Caetano do Sul, v. 19, n. 40, p. 24-38, mai./ago. 2018. Disponível em: https://seer.uscs.edu.br/index.php/revista_comunicacao_inovacao/article/view/5 175/0 Acesso: 24 abr. 2020.

ZIZEK, Slavoj (org.). Um mapa da ideologia. Rio de Janeiro: Contraponto, 1996. 